\title{
Spatial distribution, abundance and habitat use of the protected fan mussel Pinna nobilis in Souda Bay, Crete
}

\author{
Stelios Katsanevakis ${ }^{1,2, *}$, Maria Thessalou-Legaki ${ }^{2}$ \\ ${ }^{1}$ Institute of Marine Biological Resources, Hellenic Centre for Marine Research (HCMR), 46.7 km Athens-Sounio, \\ 19013 Anavyssos, Greece \\ ${ }^{2}$ Department of Zoology-Marine Biology, Faculty of Biology, University of Athens, Panepistimioupolis, 15784 Athens, Greece
}

\begin{abstract}
The spatial distribution and abundance of the endangered fan mussel Pinna nobilis was investigated in Souda Bay, Crete, Greece. A density surface modelling approach using survey data from line transects, integrated with a geographic information system, was applied to estimate the population density and abundance of the fan mussel in the study area. Marked zonation of $P$. nobilis distribution was revealed with a density peak at a depth of $\sim 15 \mathrm{~m}$ and practically zero densities in shallow areas ( $<4 \mathrm{~m}$ depth) and at depths $>30 \mathrm{~m}$. A hotspot of high density was observed in the southeastern part of the bay. The highest densities occurred in Caulerpa racemosa and Cymodocea nodosa beds, and the lowest occurred on rocky or unvegetated sandy/muddy bottoms and in Caulerpa prolifera beds. The high densities of juvenile fan mussels (almost exclusively of the first age class) observed in dense beds of the invasive alien alga C. racemosa were an indication of either preferential recruitment or reduced juvenile mortality in this habitat type. In C. nodosa beds, mostly large individuals were observed. The total abundance of the species was estimated as 130900 individuals with a $95 \%$ confidence interval of 100600 to 170400 individuals. Despite poaching, incidental killing and marine pollution, the fan mussel population of Souda Bay remains of high importance as one of the largest documented in Greece, and protection measures are urgently needed to secure its sustainability. We provide a baseline for the Souda Bay fan mussel population.
\end{abstract}

KEY WORDS: Abundance estimation - Spatial distribution · Fan mussel · Pinna nobilis · Distance sampling $\cdot$ Line transects $\cdot$ SCUBA $\cdot$ Endangered species

\section{INTRODUCTION}

The fan mussel Pinna nobilis L. is an endemic Mediterranean bivalve. It is one of the largest bivalves in the world, attaining anterio-posterior lengths of up to $120 \mathrm{~cm}$, and may live over $20 \mathrm{yr}$ (Galinou-Mitsoudi et al. 2006, Katsanevakis et al. 2008). The fan mussel typically occurs at depths between 0.5 and $60 \mathrm{~m}$, usually on soft-bottom areas overgrown by seagrass (mostly Posidonia oceanica and Cymodocea nodosa meadows), but also in unvegetated sandy areas (Katsanevakis 2005b, 2007a). Fan mussels live with the anterior portion of their shell partially buried and attached by their numerous byssus filaments to parti- cles, seagrass rhizomes and solid structures of the substratum. Reproduction takes place by means of external fertilisation. Spawning of the fan mussel occurs during late summer to early autumn (De Gaulejac 1993, Richardson et al. 1999) and its larval life spans 5 to 10 d (Butler et al. 1993).

Since ancient times, Pinna nobilis has been extensively exploited. Its flesh has been used for food, its shell as a decoration, and its byssus for the production of an extremely fine and valuable fabric, called 'sea silk'. The global population of $P$. nobilis has been greatly reduced during the past few decades as a result of recreational and commercial fishing, degradation of its main habitats and incidental killing by 
trawlers, bottom nets, or anchoring. Consequently, it has been listed as an endangered species in the Mediterranean and is under strict protection according to the Habitats Directive 92/43/EEC (Annex IV), the Protocol for Specially Protected Areas and Biological Diversity in the Mediterranean of the Barcelona Convention (Annex II) and the national laws of most Mediterranean countries. Although $P$. nobilis has become rare in many parts of the Mediterranean, important local populations still exist in the Greek seas (for review see Katsanevakis et al. 2008). However, no formal monitoring scheme of the fan mussel population has been implemented in Greece, and its spatial distribution, abundance and the temporal trends in abundance remain largely unknown.

Souda Bay is an area of intense human activities as it is one of the largest natural embayments in the Mediterranean, being an important port for freight and ferries sailing to Pireaus, and a strategic Hellenic Navy and NATO naval base. Shipping, coastal fisheries, aquaculture, tourism, and agricultural and industrial activities are among the human pressures on the Souda Bay ecosystem. There is increased concern about the degradation of the marine ecosystem of the bay, which, in 2007, led the local authorities to assign a multi-disciplinary survey to assess the environmental status of the bay. The present study is part of that survey. It aimed to assess the present status of the fan mussel population of Souda Bay, as a first step towards monitoring trends and a prerequisite for its conservation. The spatial distribution of the species and its habitat preferences were studied. Its abundance was estimated based on density surface modelling with line transect sampling via SCUBA diving (Katsanevakis 2007a).
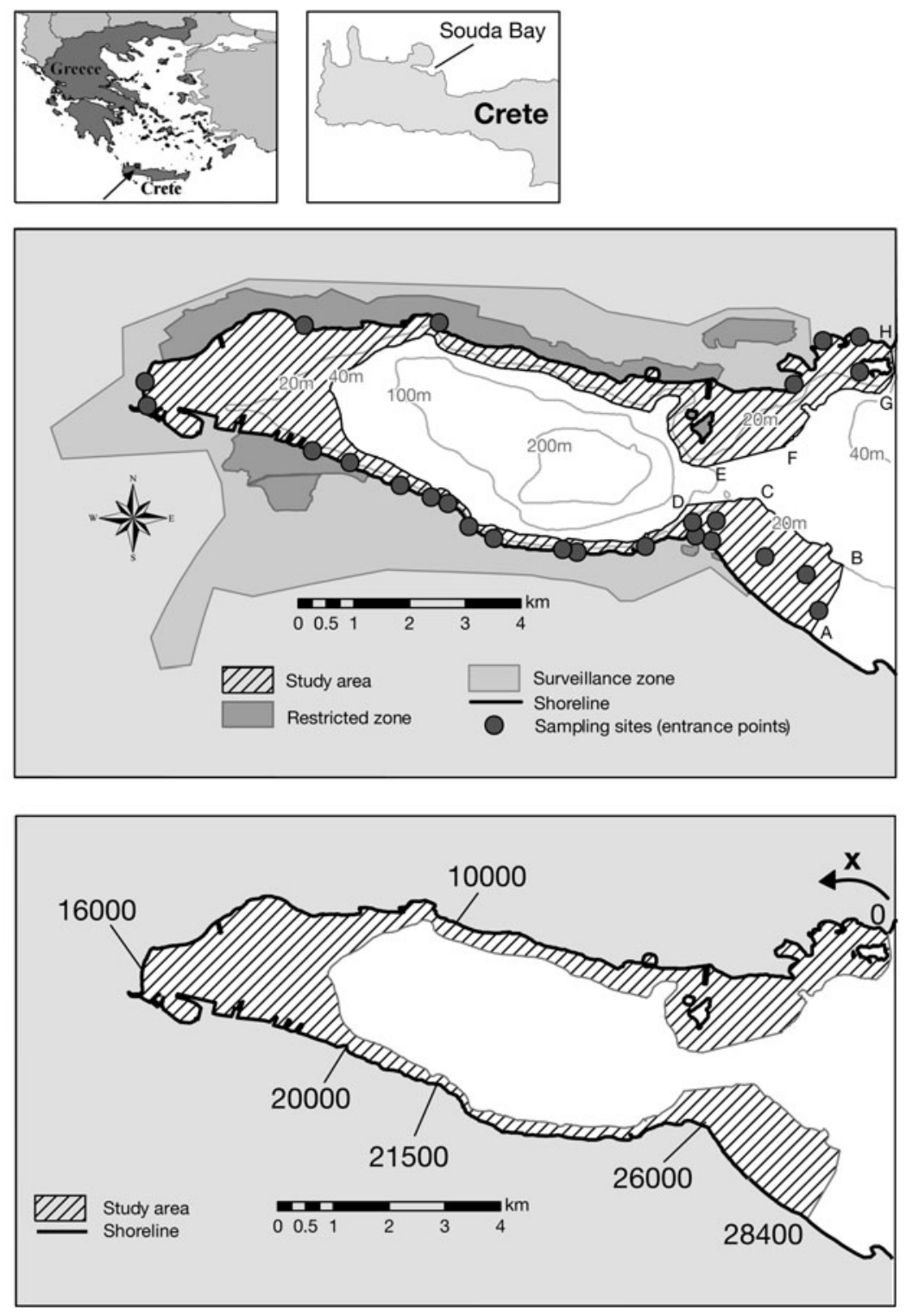

Fig. 1. Upper panel: map of the study area in Souda Bay, Crete, Greece. The 'restricted zone' is a military area and access is prohibited (NATO and Hellenic Navy base). In the 'surveillance zone' all activities are under military surveillance. Lower panel: some indicative values (in $\mathrm{m}$ ) for the location variable $(x)$, representing the distance from the north-eastern edge of the study area

\section{MATERIALS AND METHODS}

Study area. The study area was defined as the area between the coastline and the curve ABCDEFGH shown in Fig. 1. In the inner part of the bay, the study area included the region between the coastline and the $40 \mathrm{~m}$ depth contour. In the outer northern part of the bay, the study area included depths $<30 \mathrm{~m}$, while in the outer southern part it included depths $<20 \mathrm{~m}$. In the outer part of the bay, the depth limit of the study area was less than that of the inner part for safety reasons, as the region $\mathrm{BCDEFGB}$ is a shipping lane for large commercial and military vessels and, thus, diving was neither feasible nor safe.

Distance sampling. Underwater visual surveys with plot sampling, and especially strip transects, have been used extensively to estimate the density and/or abundance of benthic species. In strip transects, the plots are long, narrow strips, and the observer travels along the centre line searching for the animal of interest and counting all individuals within the strip. In plot 
sampling, the critical assumption is that all individuals present in the surveyed areas are detected. However, this assumption cannot be tested using the survey data, and to ensure that it holds to a good approximation in all habitats and environmental conditions, it may be necessary to use narrow strips, which is problematic for scarce species (Burnham \& Anderson 1984, Buckland et al. 2001) and increases the variance of density estimators (Kulbicki \& Sarramégna 1999, Buckland et al. 2001). If the assumption that all individuals present in the surveyed areas are detected is not met, there is underestimation of abundance, which is not uncommon in underwater surveys. Failure to properly account for detection probability (i.e. probability of detecting the presence of an individual within a plot) leads to negatively biased estimates of population density or abundance by a factor equal to the probability that an animal in the covered region is detected.

One of the most active areas of biometric and wildlife research is the development of methods and models to properly account for detection probability, and this is reflected in the recent proliferation of books describing these approaches (e.g. Thompson et al. 1998, Buckland et al. 2001, 2004, Williams et al. 2002, Borchers et al. 2004, Thompson 2004). Distance sampling (Buckland et al. 2001, 2004) is one such widely used method.

The main distance sampling methods are line transects and point transects. A standardised survey is conducted along a series of lines (in line transects) or points (in point transects) searching for the animals of interest. For each animal detected, the distance, $y$, from the line or point is recorded. A detection function, $g(y)$, is fitted from the set of recorded distances (Buckland et al. 2001, 2004), which is used to estimate the proportion of animals missed by the survey and, hence, estimate abundance. When the detection of individuals is difficult, a distance sampling method is typically more efficient than simple strip transect sampling. This is because densities are corrected with the use of the detection function and the sample size is larger for the same amount of effort as all detected individuals may be recorded regardless of how far they are from the line or point.

Abundance estimation and spatial distribution of the fan mussel Pinna nobilis in Souda Bay was based on the count method of Hedley \& Buckland (2004), who developed ways of improving the estimation of cetacean abundance, allowing heterogeneity in the spatial distribution of cetaceans to be modelled from standard line transect data. According to the count method, the transect lines are divided into smaller discrete units called segments, and the estimated number of detections in each unit is modelled with generalised additive modelling (GAM; Hastie \& Tibshirani 1990) using explanatory spatial covariates. Based on the spatial distri- bution of the explanatory covariates in the study area, the model-based population density surface is estimated, which by integration provides an estimation of abundance.

Field work. The survey was conducted in July and August 2007; 42 line transects were defined in Souda Bay in 25 different sites in the study area (Fig. 1) (in some sites of high fan mussel density $>1$ transect was surveyed). Military areas were undersampled, as limited access was provided only in specific sites indicated by the military authorities and under authorised supervision. Unbiased design-based inference necessitates placing the line transects in the study area randomly or on a grid of systematically spaced lines randomly superimposed on the study area. However, with a model-based approach like density surface modelling (DSM), it is not required that the line transects are located according to a formal and restrictive survey sampling scheme, although good spatial coverage of the study area is desirable. Thus, the sampling scheme that was followed and the restrictions by the military authorities are not expected to cause important bias in the estimations.

Each line transect was defined with a nylon line that was deployed using a diving reel while SCUBA diving. The line was marked with a water-resistant paint marker every metre and divided into $5 \mathrm{~m}$ segments, with water-resistant numbered signs. After deploying the line, all detected Pinna nobilis individuals within $4 \mathrm{~m}$ of the line (half of the width $W_{t}$ of the line transects) were recorded. For each observed individual, the following variables were recorded: the corresponding line segment of occurrence, its perpendicular distance from the line $\left(y_{i}\right)$, and shell size $\left(w_{i}\right)$, defined as the maximum dorso-ventral length of the shell. The latter was measured in situ with vernier calipers. The perpendicular distance from the line was measured with the use of a $2 \mathrm{~m}$ plastic rod, bearing marks every $5 \mathrm{~cm}$. The location of an individual was defined as the midpoint of the section of the shell by the seabed plane. In addition, at the mid-point of each segment of the line transect the exact depth was measured using the electronic depth meter of a diving computer. The dominant habitat type of each segment was also recorded. Six different habitat types were identified: unvegetated sandy/muddy bottoms (UN), Cymodocea nodosa beds (CN), Caulerpa prolifera beds (CP), Caulerpa racemosa beds (CR), Halophila stipulacea beds (HS) and rocky substrate (R). The length of the line transects varied between 30 and $240 \mathrm{~m}$, depending on the depth, the depth gradient and the fan mussel density.

Detection function modelling. The detection function of Pinna nobilis in the bay, $g(y)$, gives the probability of detecting an individual given that it is at a distance $y$ from the line; it was estimated from the dis- 
tance data according to Buckland et al. (2001), using Distance 6.0 software (Thomas et al. 2006). Specifically, 2 functions were considered as candidate detection functions: the 1-parameter, half-normal function $g(y)=\exp \left(-y^{2} / 2 \sigma^{2}\right)$ and the 2-parameter, hazard-rate function $g(y)=1-\exp \left[-(y / \sigma)^{-b}\right]$, where $\sigma$ is a scale parameter and $b$ a shape parameter.

Eight models were included in the set of candidate models (Table 1). The half-normal function was used in models $g_{1}$ to $g_{4}$, while the hazard-rate function was used in models $g_{5}$ to $g_{8}$. In models $g_{1}$ and $g_{5}$, the scale parameter $\sigma$ was considered constant, while in the other models it was a function of 1 or 2 covariates. Specifically, it was assumed that the covariates $v_{j}$ affect detectability via the scale term $\sigma$, according to the relationship $\sigma=\exp \left(\beta_{0}+\Sigma \beta_{j} v_{j}\right)$, where $\beta$ represents estimable parameters (Marques \& Buckland 2004). The size $w$ of Pinna nobilis (models $g_{2}$ and $g_{6}$ ), habitat type (models $g_{3}$ and $g_{7}$ ), or both (models $g_{4}$ and $g_{8}$ ) were included as covariates in the candidate models. For detection function modelling, the 6 identified habitat types were aggregated into just 2 groups, with the first representing $\mathrm{CNs}$ and the second all other habitat types (O). The reasoning behind this grouping was that Caulerpa prolifera, C. racemosa and Halophila stipulacea had similar sizes and frond densities; thus, detectability was not expected to differ among these habitats. However, CNs were denser and their leaves were much longer; thus, fan mussels were more difficult to detect. In Rs and UNs only 3 fan mussel individuals were detected. This was quite a low sample size to model separate detection functions; thus, these habitats were also included in the O group.

The small-sample, bias-corrected form $\mathrm{AIC}_{\mathrm{c}}$ (Hurvich \& Tsai 1989) of the Akaike information criterion (Akaike 1973, Burnham \& Anderson 2002) was used for model selection among the set of candidate models. Specifically, $\mathrm{AIC}_{\mathrm{c}}=\mathrm{AIC}+2 K(K+1) /(n-K-1)$ and $\mathrm{AIC}=$ $-2 \ln (\mathcal{L}(\hat{\boldsymbol{\theta}}$ ldata $))+2 K$, where $\ln (\mathcal{L}(\hat{\boldsymbol{\theta}} \mid$ data $))$ is the numerical value of the log-likelihood (natural logarithm) at its maximum point, $K$ is the number of estimable parameters of the model, and $\hat{\boldsymbol{\theta}}$ is the vector of the model's esti- mated parameters. The model with the smallest $\mathrm{AIC}_{\mathrm{C}}$ value $\left(\mathrm{AIC}_{\mathrm{c}, \min }\right)$ was selected as the 'best' among the models tested. The $\mathrm{AIC}_{\mathrm{c}}$ differences, $\Delta_{i}=\mathrm{AIC}_{c, i}-$ $\mathrm{AIC}_{c, \min }$, were computed over all candidate models. Models with $\Delta_{i}>10$ have essentially no support and might be omitted from further consideration, while models with $\Delta_{i}<2$ have substantial support (Burnham \& Anderson 2002). Goodness-of-fit of the best model was assessed with Q-Q plots, and the Cramér-von-Mises test-weighted to give higher weight to distances near zero-was performed, as described by Burnham et al. (2004). Only the best model was used for DSM.

Density surface modelling. Habitat type, $H$, was used as a categorical variable in modelling the density surface of Pinna nobilis in Souda Bay. Two continuous predictor variables were used in the DSM of $P$. nobilis. These 2 variables were depth $(d)$ and a location variable $(x)$ representing the distance from the northeastern edge of the study area (Point G), when moving anticlockwise along the shoreline (Fig. 1). The study area was actually a narrow strip with the $x$-axis in the largest dimension and a $q$-axis perpendicular to $x$. The $q$ variable was highly correlated with depth. Multicollinearity in the covariates indicates that a substantial part of the information in one or more of the predictor variables is redundant, which makes it difficult to separate the effects of the different variables on the response variable. Because depth is quite an important predictor for $P$. nobilis distribution (Katsanevakis 2005b, 2007 a), $d$ was chosen over $q$, which was not considered as a covariate in DSM.

The surveyed line transects were divided into $T 5 \mathrm{~m}$ (l) segments, and the number of Pinna nobilis individuals detected within each segment was denoted by $n_{i r}$ $i=1, \ldots, T$. The probability of detecting animal $j$ on segment $i$ was symbolised by $\hat{p}_{i j}$ and was obtained from the estimated detection function. The total number of individuals within segment $i$ was estimated using the Horvitz-Thompson-like estimator $\hat{n}_{i}=\sum_{j=1}^{n_{i}} \frac{1}{\hat{p}_{i j}}$ (Hedley et al. 2004). In the current context, in all candidate models for the detection function, detectability was considered

Table 1. Summary of the parameterisation of the 8 candidate models $g_{i}$ of the detection function and of the bias-corrected form of the Akaike information criterion $\left(\mathrm{AIC}_{\mathrm{c}}\right)$, Akaike differences $\left(\Delta_{i}\right)$, estimated average probability of detection $\left(P_{\mathrm{a}}\right.$, mean $\left.\pm \mathrm{SE}\right)$, and effective strip half-width $(\mu$, mean $\pm \mathrm{SE})$

\begin{tabular}{|llcccccc|}
\hline \multirow{2}{*}{ Model } & Key-function & Covariate & No. of parameters & $\mathrm{AIC}_{\mathrm{c}}$ & $\Delta_{i}$ & $P_{\mathrm{a}}$ & $\mu(\mathrm{cm})$ \\
\hline$g_{1}$ & Half-normal & - & 1 & 1974.3 & 31.8 & $0.568 \pm 0.034$ & $227.0 \pm 13.4$ \\
$g_{2}$ & Half-normal & Size & 2 & 1943.1 & 0.6 & $0.504 \pm 0.031$ & $201.5 \pm 12.5$ \\
$g_{3}$ & Half-normal & Habitat & 2 & 1966.4 & 23.9 & $0.552 \pm 0.030$ & $220.6 \pm 11.9$ \\
$g_{4}$ & Half-normal & Size + habitat & 3 & 1944.0 & 1.5 & $0.503 \pm 0.032$ & $201.1 \pm 12.6$ \\
$g_{5}$ & Hazard-rate & - & 2 & 1966.4 & 23.9 & $0.356 \pm 0.066$ & $142.3 \pm 26.4$ \\
$g_{6}$ & Hazard-rate & Size & 3 & 1942.5 & 0.0 & $0.447 \pm 0.032$ & $178.6 \pm 12.8$ \\
$g_{7}$ & Hazard-rate & Habitat & 3 & 1957.6 & 15.1 & $0.368 \pm 0.026$ & $147.4 \pm 10.3$ \\
$g_{8}$ & Hazard-rate & Size + habitat & 4 & 1943.5 & 1.0 & $0.432 \pm 0.032$ & $172.9 \pm 12.7$ \\
\hline
\end{tabular}


independent of any spatial covariates; thus, the $i$ subscript in $\hat{p}_{i j}$ may be eliminated, i.e. $\hat{p}_{i j}=\hat{p}_{j}$.

The estimated values of abundance in each segment were related to the spatial covariates using GAMs (Hastie \& Tibshirani 1990), according to the formulation $f\left(\mathrm{E}\left[\hat{n}_{i}\right] / 2 W_{t} l\right)=c+\sum_{m} s_{m}\left(z_{m i}\right)+\sum_{r} F_{r i}$, where $f$ is the link function, $C$ is the intercept, $s_{m}(\cdot)$ is the 1-dimensional smooth function for predictor variable $m, z_{m i}$ is the value of predictor variable $m$ for segment $i, F_{r}$ are categorical predictors, and $a=2 W_{t} l$ is the covered area of the segment. The logarithmic link (which ensures positive values of the mean response) and a quasi-Poisson error distribution were used. With a logarithmic link the above equation becomes $\ln \left(\mathrm{E}\left[\hat{n}_{i}\right]\right)=c+\sum_{m} s_{m}\left(z_{m i}\right)+\ln (a)$. The smooth function $s_{m}(\cdot)$ was represented using cubic regression splines, estimated by penalised iterative least squares (Wood 2006). The optimum degree of smoothing was defined by generalised cross validation (GCV).

Eight different GAMs, $h_{i}, i=0$ to 7 , were fitted. Model $h_{0}$ was the null model, with no predictor variable. In models $h_{1}, h_{2}$ and $h_{4}$ only 1 predictor $(m=1)$ was included ( $d, x$ and $H$, respectively), in models $h_{3}$ $h_{5}$ and $h_{6} 2$ predictors $(m=2)$ were used $\left(d+x_{1} H+d\right.$ and $H+x_{1}$, respectively) and in $h_{7}$ (full model) all 3 predictors were included $(m=3)$. Model selection among the set of candidate DSMs was conducted based on their GCV score (Wood 2006). For GAM, the package mgCV (Wood 2000, 2006) was used in R Ver. 2.5.1 (R Development Core Team 2006).

Abundance estimation. Using ArcMap 8.1 software (ESRI), a prediction grid was created on the map of the study area by dividing it into 89188 square cells of $165.1 \mathrm{~m}^{2}$ each. The abundance of Pinna nobilis in the study area was estimated as the sum of $E\left[\hat{n}_{r}\right]$ in each cell $r$ of the prediction grid, i.e. $\hat{N}=\sum_{r} \mathrm{E}\left[\hat{n}_{r}\right]$, where $\mathrm{E}\left[\hat{n}_{r}\right]$ were predictions according to the selected spatial density model $h_{i}$ (where in the offset term, the covered area of segment a was replaced by the size of the prediction cell). The above abundance estimation was conducted using the DSM analysis engine of the Distance 6.0 software (Thomas et al. 2006). Based on the predictions $\mathrm{E}\left[\hat{n}_{r}\right]$, a distribution map of $P$. nobilis in Souda Bay was produced using ArcMap 8.1.

There are 2 variance components to the final abundance estimate, one component arising from the detection function model and a second one from the DSM. It was assumed that these components were independent, and the delta method (Seber 1982) was used to estimate the total variance, according to the relationship $[c V(\hat{N})]^{2}=[c V(\hat{p})]^{2}+\left[c V\left(\hat{N}_{\text {DSM }}\right)\right]^{2}$, where $c v(\hat{p})$ is the coefficient of variation of the estimator of detection probability and $C V\left(\hat{N}_{\mathrm{DSM}}\right)$ is the coefficient of variation related to DSM. The first component was obtained analytically according to Buckland et al. (2001). For the second component, a nonparametric bootstrap approach was followed (Efron \& Tibshirani 1993), with sample size $B=999$. The bootstrap approach used a moving block of $m$ segments as a sampling unit, large enough so that segments more than $m$ units apart would be independent and small enough so that spatial correlation present in segments less than $m$ units apart would be preserved. The block size $m$ was estimated by examining the variogram of the deviance residuals (geoR package in R). Unmodelled spatial autocorrelation results in a variogram that increases sharply before eventually reaching a plateau; the starting point of the plateau would define the block size $m$.

\section{RESULTS}

\section{Detection function modelling}

A total of 177 fan mussel Pinna nobilis individuals were recorded in the line transects. The best model of the detection function among those tested (based on $\mathrm{AIC}_{\mathrm{C}}$ ) was the hazard-rate function with shell size $w$ of the fan mussel as a scale covariate $\left(g_{6}\right)$ (Table 1$)$. This model provided a good absolute fit, as assessed by the $\mathrm{Q}-\mathrm{Q}$ plot and the weighted Cramér-von Mises test $(\mathrm{p}=$ 0.47). All models that did not include shell size as a covariate $\left(g_{1}, g_{3}, g_{5}\right.$ and $\left.g_{7}\right)$ had essentially no support by the data $\left(\Delta_{i}>15\right)$. The half-normal model with size as a covariate $\left(g_{2}\right)$, as well as models with both size and habitat type as covariates $\left(g_{4}\right.$ and $\left.g_{8}\right)$, all had substantial support by the data and gave similar results for the average probability of detection and the effective strip half-width (Table 1).

The best model $\left(g_{6}\right)$ is given by the equation:

$$
\begin{aligned}
g(y) & =1-\exp \left[-\left(\frac{y}{\exp \left(\beta_{0}+\beta_{1} \cdot w\right)}\right)^{-b}\right] \\
& =1-\exp \left[-\left(\frac{y}{\exp (3.739+0.131 \cdot w)}\right)^{-1.995}\right]
\end{aligned}
$$

where the distance from the line $(y)$ and shell size $(w)$ are in centimetres (Fig. 2).

\section{Density surface modelling - Habitat use}

The best DSM was $h_{7}$, which included univariate smooth functions of depth $(d)$ and location $(x)$, as well as habitat type $(H)$ as a categorical predictor (Table 2). The expression of $h_{7}$ was $\ln \left(\mathrm{E}\left[\hat{n}_{i}\right]\right)=H+s_{1}(d)+s_{2}(x)+$ $\ln (a)$, where $a=40 \mathrm{~m}^{2}$, and the smooth functions $S_{i \text {, as }}$ well as the estimates of $H$ at the different levels of habitat type, are given in Fig. 3. The fan mussel population density peaked at a depth of $\sim 15 \mathrm{~m}$ and was practically zero in shallow areas $(<4 \mathrm{~m}$ depth) and at depths $>30 \mathrm{~m}$. Regarding the spatial coordinate $x_{r}$ 


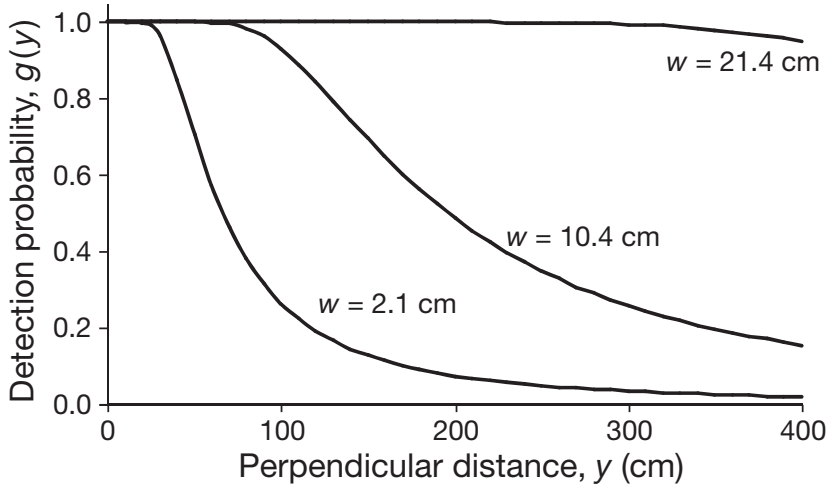

Fig. 2. Pinna nobilis. The best detection function model $\left(g_{6}\right)$ for 3 different values of fan mussel shell sizes corresponding to the minimum $(w=2.1 \mathrm{~cm})$, mean $(w=10.4 \mathrm{~cm})$ and maximum $(w=21.4 \mathrm{~cm})$ shell size measured during the present survey

3 sites of peak density were observed, at $x \sim 9600$, 21500 and $26650 \mathrm{~m}$. The highest densities were observed in CRs and CNs, and the lowest, on Rs, UNs, and in CPs. No fan mussels were recorded in the line transects conducted in the 2 westernmost sampling sites in the bay.

The size distribution of Pinna nobilis substantially differed among habitats (Fig. 4). Individuals with $w<$ $8 \mathrm{~cm}$ are presumed to belong to the first age class (Katsanevakis 2005b) and they were mostly found in CRs. On the contrary, large individuals were rare in $\mathrm{CRs}$, and were mainly found in CNs and CPs.

\section{Abundance estimation}

Although $h_{7}$ was the best among the candidate models (Table 2), an abundance estimation could not be

Table 2. Evaluation of the 8 density surface models, based on their generalised cross validation (GCV) score. The percentage of deviance explained by the model and the corresponding estimated degrees of freedom are also given. The fan mussel Pinna nobilis abundance estimations in the study area are provided for models $h_{0}$ to $h_{3}$. Onedimensional smooth function of depth $s(d)$ and location $s(x)$ (see Fig. 1); $H$ : habitat type

\begin{tabular}{|c|c|c|c|c|c|}
\hline & Model & $\begin{array}{l}\text { GCV } \\
\text { score }\end{array}$ & $\begin{array}{c}\text { Deviance } \\
\text { explained } \\
(\%)\end{array}$ & $\begin{array}{l}\text { Estimated } \\
\text { degrees } \\
\text { of freedom }\end{array}$ & $\begin{array}{l}\text { Abundance } \\
\text { estimation }\end{array}$ \\
\hline$h_{0}$ & Null & 10.10 & 0.0 & 1.0 & 156189 \\
\hline$h_{1}$ & $s(d)$ & 1.58 & 37.0 & 7.2 & 118560 \\
\hline$h_{2}$ & $s(x)$ & 1.69 & 33.3 & 11.7 & 185182 \\
\hline$h_{3}$ & $s(d)+s(x)$ & 1.19 & 53.5 & 16.3 & 130917 \\
\hline$h_{4}$ & $\mathrm{H}$ & 4.85 & 32.5 & 6.0 & - \\
\hline$h_{5}$ & $H+s(d)$ & 1.09 & 56.8 & 12.6 & - \\
\hline$h_{6}$ & $H+s(x)$ & 1.26 & 50.7 & 17.4 & - \\
\hline$h_{7}$ & $H+s(d)+s(x)$ & 0.89 & 65.6 & 22.9 & - \\
\hline
\end{tabular}

based on it, as there was no habitat mapping available for the study area. Thus, the abundance estimation was based on the best model among those not including $H_{\text {, }}$ namely $h_{3}$. The expression of $h_{3}$ was $\ln \left(\mathrm{E}\left[\hat{n}_{i}\right]\right)=c+s_{1}(d)$ $+s_{2}(x)+\ln (a)$, where $c=-7.13 \pm 0.28( \pm \mathrm{SE}), a=40 \mathrm{~m}^{2}$, and the smooth functions $s_{i}$ are given in Fig. 5. The observed patterns were quite similar to those of $h_{7}$, but the depth of peak density was shifted to slightly lower values $(\sim 13.8 \mathrm{~m})$, and the peak at location $x=26650 \mathrm{~m}$ was more intense.

The variogram of the deviance residuals (Fig. 6) suggested no spatial autocorrelation, and thus, for parametric bootstrap, the segment was the sampling unit, i.e. $m=1$. Based on $h_{3}$, the fan mussel abundance in the study area was estimated to be $\hat{N}=130900$, with $C V(\hat{N})=13.5 \%$. The variation component due to uncertainty in the estimation of the detection function was $C V(\hat{p})=11.6 \%$, while the component due to DSM was $C V\left(\hat{N}_{\text {DSM }}\right)=6.9 \%$. The $95 \%$ CI of the abundance of Pinna nobilis in the study area was from 100600 to 170400 ind. The density surface map of $P$. nobilis according to $h_{3}$ is given in Fig. 7 . The highest densities and the largest percentage of total abundance were observed in the south-eastern part of the study area.

\section{DISCUSSION}

A few decades ago, Pinna nobilis was quite abundant in the Greek coastal region, but its population has now greatly decreased (Katsanevakis et al. 2008). Despite the existing legal framework for its protection, poaching or incidental killing of fan mussels poses a significant risk for many local populations. In the marine Lake Vouliagmeni (Korinthiakos Gulf, Greece), the local fan mussel population declined by $48 \%$ between 2004 and 2007, due to poaching and recruitment failure (Katsanevakis 2009a). In Souda Bay, there is an active coastal fishery, and $P$. nobilis is a common by-catch in trammel nets. In shallow waters, free divers continue to exploit fan mussels and are either unaware of or ignore the fact that the species is legally protected. In other Greek areas, fishing mortality has been found to be much higher than natural mortality in adult individuals, and is an important driver of the spatial distribution of the species and its population viability (Katsanevakis 2007b, 2009b).

The observed pattern of population density with depth in Souda Bay was similar to that observed in Lake Vouliagmeni (Katsanevakis 2005b, 2007a), where there was a main density peak at depths between 12 and $13 \mathrm{~m}$ and practically zero density at depths $>22 \mathrm{~m}$. It seems that 

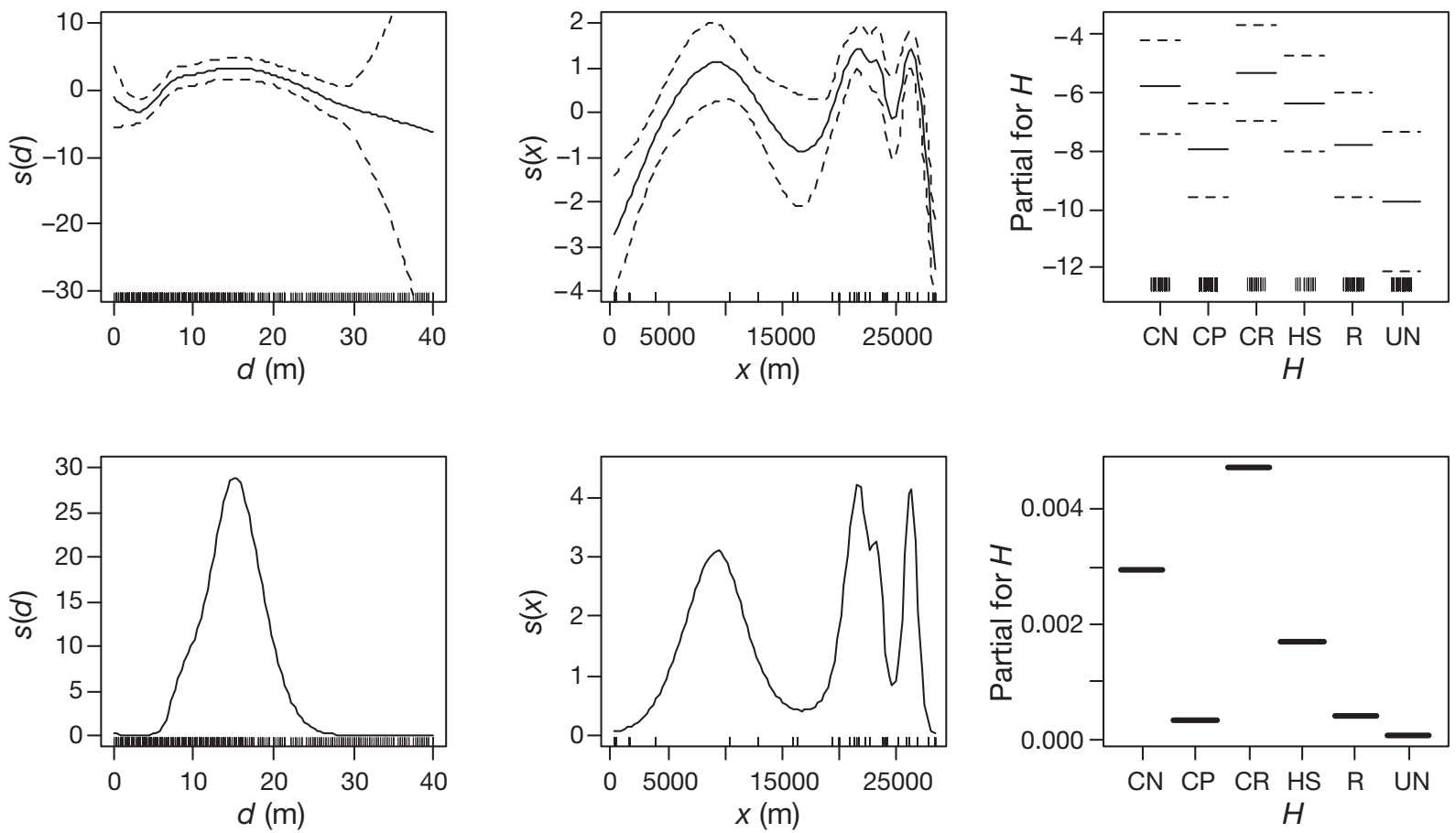

Fig. 3. Pinna nobilis. Estimated smooth terms $s(d)$ and $s(x)$, and the values of the categorical predictor $H$ (habitat type), for the $h_{7}$ model of $P$. nobilis abundance in $8 \times 5 \mathrm{~m}$ plots in Souda Bay. Upper panels: smooth terms are given in the linear predictor scale and the corresponding $95 \%$ confidence intervals are given with dotted lines. Lower panels: smooth terms are given in the response scale (i.e. smooth terms were exp-transformed). A 1-dimensional scatterplot is given at the bottom of each graph, using a vertical bar as the plotting symbol, to illustrate the distribution of available data. CN: Cymodocea nodosa beds; CP: Caulerpa prolifera beds; CR: Caulerpa racemosa beds; HS: Halophila stipulacea beds; R: rocky substrate; UN: unvegetated sandy/muddy bottoms

Pinna nobilis is mostly restricted to the shallow coastal zone and, after a density peak, its density declines with depth. The lower depth limit, which was $\sim 22 \mathrm{~m}$ in Lake Vouliagmeni and $\sim 30 \mathrm{~m}$ in Souda Bay, probably depends on local conditions. The low population density of fan mussels in the shallower depths of their depth range has been attributed to 2 main factors, poaching by free divers

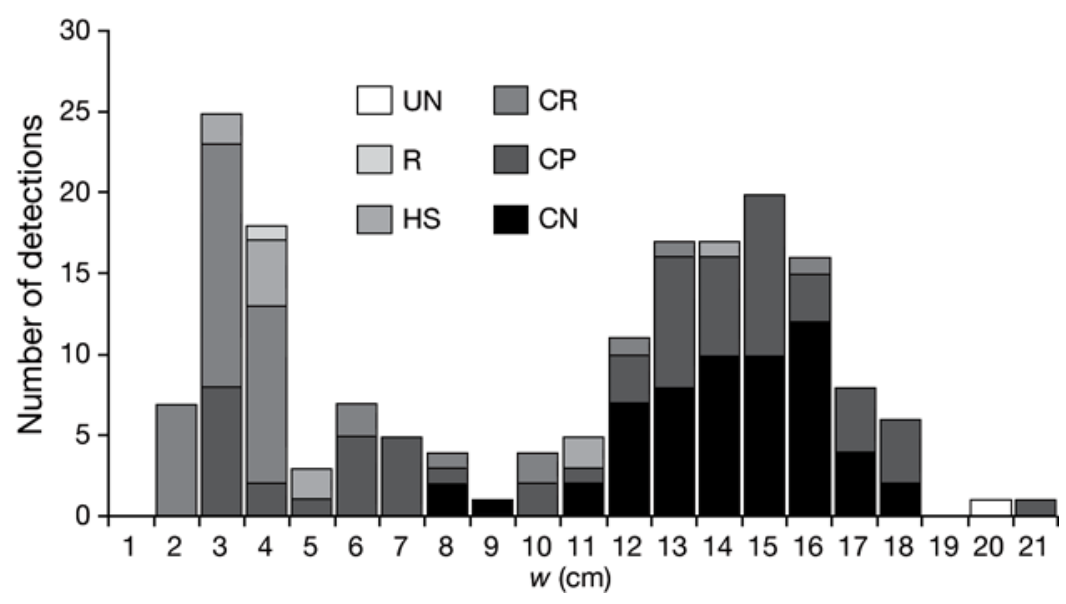

Fig. 4. Pinna nobilis. Size distribution in the various habitat types of the study area. $w$ : shell size; UN: unvegetated sandy/muddy bottoms; R: rocky bottoms; HS: Halophila stipulacea beds; CR: Caulerpa racemosa beds; CP: Caulerpa prolifera beds; CN: Cymodocea nodosa beds
(Katsanevakis 2007b) and mortality attributed to hydrodynamic stress caused by the water flow produced by waves (García-March et al. 2007).

The highest densities of juveniles were observed in CRs, indicating that this habitat might be preferential for recruitment or a habitat of low natural mortality of the recruits. Caulerpa racemosa var. cylindracea is an invasive variety of the species, introduced to the Mediterranean from south-western Australia at the beginning of the 1990s (Verlaque et al. 2003, Klein \& Verlaque 2008). This new variety has rapidly spread throughout the whole Mediterranean basin, reaching as far as the Canary Islands in the eastern Atlantic Ocean, and its rate of expansion appears to be among the most dramatic ever recorded (Streftaris \& Zenetos 2006, Klein \& Verlaque 2008). Surprisingly, the ecological and economic impacts of $C$. racemosa are largely unassessed, although severe impact on benthic fauna is predicted (Klein \& Verlaque 2008, Vázquez-Luis et al. 2008). C. racemosa causes accumulation of detritus and provides a multilayer structure through its horizontal (with 

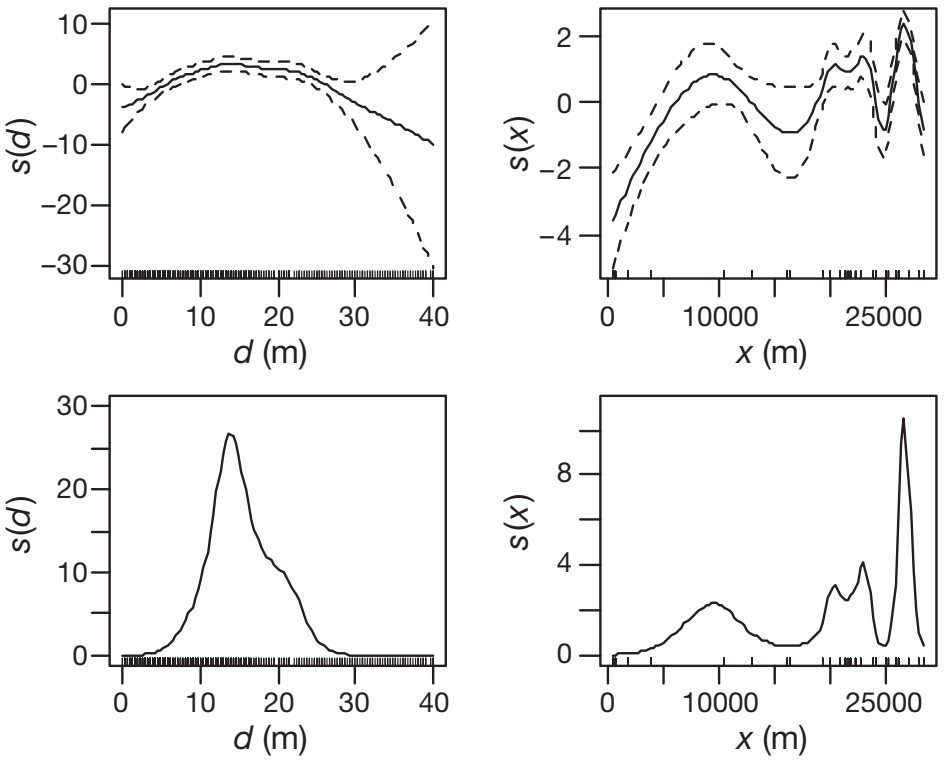

Fig. 5. Pinna nobilis. As for Fig. 3, but for the $h_{3}$ model

stolons) and vertical (with rhizoids and fronds) growth that traps the sediment (Piazzi et al. 2001, Vázquez-Luis et al. 2008). The settlement and attachment of fan mussel larvae is possibly favoured by the more stable and structured sediment in CRs in relation to UNs. The survival of fan mussel recruits is significantly affected by the abundance of large megafaunal predators such as decapods or gastropods. If C. racemosa negatively affects the abundance of such benthic predators, it might indirectly enhance fan mussel survival. However, this remains speculative, and further investigation is needed to explain the increased abundance of fan mussel juveniles in CRs. The most extensive CRs were observed in the southeast part of the study area. The absence of large individuals in CRs could be partly explained by the increased mortality due to fishing activity with bottom nets in this specific location, in contrast to other locations in the bay where fishing activity is reduced, either due to restricted access or adverse conditions (e.g. rough and/or steep bottoms).

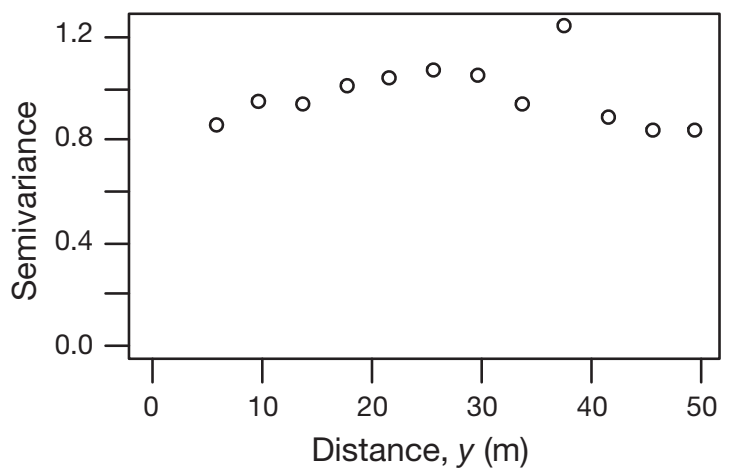

Fig. 6. Variogram of the deviance residuals of model $h_{3}$
Fan mussel population density estimates have been reported for various locations in the Mediterranean; reviews of such data are provided by Galinou-Mitsoudi et al. (2006) and Rabaoui et al. (2007). However, these density estimates were mainly based on plot sampling (usually strip transects), and there was no way to ensure that all individuals in the plot were detected. This is an issue especially (but not exclusively) for small individuals. In the UNs of Lake Vouliagmeni, detectability in $2 \mathrm{~m}$ wide strips was $\sim 50 \%$ for individuals of the first age class and close to $100 \%$ for the other age classes (Katsanevakis 2005b). In the present study (with a variety of habitat types), the average detection probability was $\sim 45 \%$ and was much less for small individuals (Fig. 2).

Apart from Souda Bay, the only fan mussel population for which abundance has been estimated is the one in Lake Vouliagmeni (Katsanevakis 2005b, 2007a, 2009a,b). Abundance estimates and, more importantly, trends in such estimates are a prerequisite for assessing the status of the species and proposing prompt measures to ensure the viability of local populations. Apart from Pinna nobilis, reliable abundance estimations are lacking for the vast majority of protected marine benthic species, mainly for 2 reasons. First of all, motivations for nature protection are mostly 'egocentric' and concentrate on maximising and sustaining the exploitation of nature for human benefit (Kinne 2006). National and international financing of ecological research focuses on the management, stock assessment and conservation of commercially important species, whereas funding of research on endangered species is limited. Second, appropriate cost-effective, unbiased and precise methodologies for estimating abundance of many endangered species are lacking or wildlife managers are not familiar with existing techniques. In this respect, distance sampling with SCUBA has proven to be a useful and effective technique to estimate the abundance of

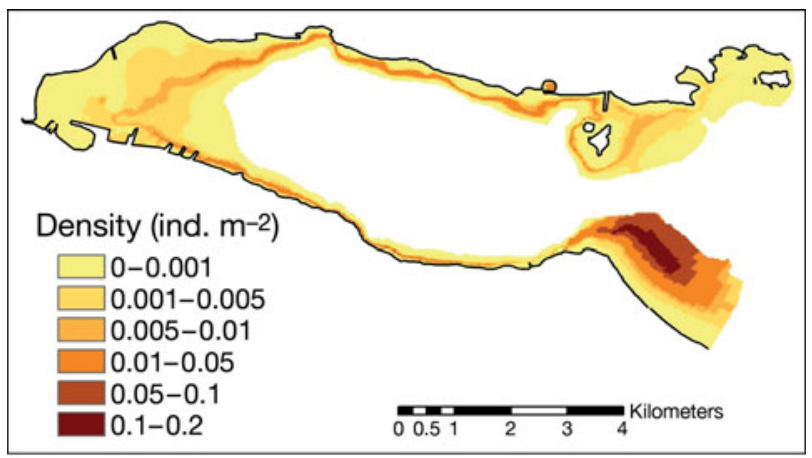

Fig. 7. Pinna nobilis. Fan mussel population density, Souda Bay 
aquatic benthic species in shallow areas (such as coral reefs, sea grass meadows, lagoons, coastal rocky reefs, muddy, or sandy habitats). Up to now, distance sampling has been used to study populations of marine bivalves (Katsanevakis 2005a,b, 2007a), sea anemones (Katsanevakis \& Thessalou-Legaki 2007), marine reef fish (Thresher \& Gunn 1986, Letourneur et al. 1998, Kulbicki \& Sarramégna 1999) and freshwater fish (Ensign et al. 1995, Pink et al. 2007). It is a nondestructive method suitable for endangered species and protected habitats and deserves serious consideration by aquatic wildlife managers (Katsanevakis 2009a).

Since many local fan mussel populations have greatly declined or collapsed throughout the Mediterranean (e.g. Vicente \& Moreteau 1991, Centoducati et al. 2007), conserving the remaining large local populations is crucial. Fan mussels reproduce by external fertilisation, and reproductive success depends on the proximity of other individuals that are spawning synchronously. When a population becomes sparse (as is the case for most fan mussel populations in the Mediterranean) failure of fertilisation becomes a critical issue for the survival of the species. The planktonic period is short (Butler et al. 1993); hence, populations (especially those in closed embayments) that are relatively isolated are not easily recolonised if depleted.

The fan mussel population in Souda Bay is quite important because of its overall size and high population density in the outer bay, which in some locations exceeded 0.2 ind. $\mathrm{m}^{-2}$, a figure ranking among the highest in the Mediterranean (Galinou-Mitsoudi et al. 2006, Centoducati et al. 2007, Rabaoui et al. 2007, Addis et al. 2009). Local fishermen and recreational divers (that were interviewed within the framework of this survey) stressed that fan mussels have now almost disappeared from areas where they used to be quite abundant from 10 to $15 \mathrm{yr}$ ago, especially in the western part of the bay. In accordance to the above belief, in the present study, fan mussel densities were found to be much lower than expected according to the availability of favourable bottoms in the western part of the bay (depth range and substrate). In this area, high concentrations of polycyclic aromatic hydrocarbons and aliphatic hydrocarbons were detected in the surface sediments, originating from oil pollution, as well as high concentrations of $\mathrm{Cu}$ and $\mathrm{Zn}$ (M. Dassenakis et al. unpubl. data). Oil pollution events are not uncommon in the bay, and the latest large-scale incident occurred in August 2001, after a leak in an oil pipe at the Hellenic naval base, on the southwest coast of the bay. Thus, marine pollution has probably contributed to the disappearance of fan mussels from the western part of the bay. Similarly, in the severely polluted Mar Grande of Taranto (Ionian Sea, Italy), an area with historically high fan mussel abundance, extremely low fan mussel densities were recently recorded by Centoducati et al. (2007). However, in the absence of previous monitoring in Souda Bay, the extent and causes of the population decline of the fan mussel population are based on anecdotal information and should be treated as indications and not scientific evidence.

Despite poaching, incidental killing and possible effects of marine pollution, the Souda fan mussel population remains of high importance, and measures are urgently needed to reverse the declining trend and protect its habitat, in accordance with the relevant legislation.

Acknowledgements. The present study was conducted within the framework of the project 'Investigation of the environmental status of Souda Bay', which was financed by the Municipality of Souda. The Hellenic Navy kindly provided the necessary permission to conduct a limited number of dives within the restricted military area of the bay. We thank E. Rexstad for reviewing an earlier version of the manuscript and providing useful comments, and 3 anonymous reviewers for their helpful remarks.

\section{LITERATURE CITED}

Addis P, Secci M, Brundu G, Manunza A, Corrias S, Cau A (2009) Density, size structure, shell orientation and epibiontic colonization of the fan mussel Pinna nobilis L.; 1758 (Mollusca: Bivalvia) in three contrasting habitats in an estuarine area of Sardinia (W Mediterranean). Sci Mar 73:143-152

Akaike H (1973) Information theory as an extension of the maximum likelihood principle. In: Petrov BN, Csaki F (eds) Pro 2nd Int Symposium on Information Theory. Akademiai Kiado, Budapest, p 267-281

Borchers DL, Buckland ST, Zucchini W (2004) Estimating animal abundance. Springer-Verlag, London

Buckland ST, Anderson DR, Burnham KP, Laake JL, Borchers DL, Thomas L (2001) Introduction to distance sampling: estimating abundance of biological populations. Oxford University Press, New York

Buckland ST, Anderson DR, Burnham KP, Laake JL, Borchers DL, Thomas L (2004) Advanced distance sampling: estimating abundance of biological populations. Oxford University Press, New York

> Burnham KP, Anderson DR (1984) The need for distance data in transect counts. J Wildl Manag 48:1248-1254

Burnham KP, Anderson D (2002) Model selection and multimodel inference. Springer, Berlin

Burnham KP, Buckland ST, Laake JL, Borchers DL, Marques TA, Bishop JRB, Thomas L (2004) Further topics in distance sampling. In: Buckland ST, Anderson DR, Burnham KP, Laake JL, Borchers DL, Thomas L (eds) Advanced distance sampling: estimating abundance of biological populations. Oxford University Press, New York, p 307-392

Butler A, Vicente N, de Gaulejac B (1993) Ecology of the pteroid bivalves Pinna bicolor and Pinna nobilis L. Mar Life 3:37-45

Centoducati G, Tarsitano E, Bottalico A, Marvulli M, Lai OR, Crescenzo G (2007) Monitoring of the endangered Pinna nobilis Linné, 1758 in the Mar Grande of Taranto (Ionian Sea, Italy). Environ Monit Assess 131:339-347

De Gaulejac B (1993) Etude écophysiologique du mollusque bivalve méditerranéen Pinna nobilis L.: reproduction; croissance; respiration. PhD thesis, Université d'Aix-Marseille III, 
Marseille

Efron B, Tibshirani RJ (1993) An introduction to the bootstrap (monographs on statistics and applied probability). Chapman \& Hall/CRC, New York

Ensign WE, Angermeier PL, Dolloff CA (1995) Use of line transect methods to estimate abundance of benthic stream fishes. Can J Fish Aquat Sci 52:213-222

Galinou-Mitsoudi S, Vlahavas G, Papoutsi O (2006) Population study of the protected bivalve Pinna nobilis (Linaeus, 1758) in Thermaikos Gulf (North Aegean Sea). J Biol Res (Thessaloniki) 5:47-53

García-March JR, Perez-Rojas L, García-Carrascosa AM (2007) Influence of hydrodynamic forces on population structure of Pinna nobilis L., 1758 (Mollusca: Bivalvia): the critical combination of drag force, water depth, shell size and orientation. J Exp Mar Biol Ecol 342:202-212

Hastie TJ, Tibshirani RJ (1990) Generalized additive models (monographs on statistics and applied probability). Chapman \& Hall, London

- Hedley SL, Buckland ST (2004) Spatial models for line transect sampling. J Agric Biol Environ Stat 9:181-199

Hedley SL, Buckland ST, Borchers DL (2004) Spatial distance sampling models. In: Buckland ST, Anderson DR, Burnham KP, Laake JL, Borchers DL, Thomas L (eds) Advanced distance sampling: estimating abundance of biological populations. Oxford University Press, New York, p 48-70

Hurvich CM, Tsai CL (1989) Regression and time-series model selection in small samples. Biometrika 76:297-307

Katsanevakis S (2005a) Abundance and spatial distribution of the Mediterranean scallop, Pecten jacobaeus, in a marine lake. Fish Res 76:417-429

Katsanevakis S (2005b) Population ecology of the endangered fan mussel Pinna nobilis in a marine lake. Endang Species Res 1:51-59

Katsanevakis S (2007a) Density surface modelling with line transect sampling as a tool for abundance estimation of marine benthic species: the Pinna nobilis example in a marine lake. Mar Biol 152:77-85

Katsanevakis S (2007b) Growth and mortality rates of the fan mussel Pinna nobilis in Lake Vouliagmeni (Korinthiakos Gulf, Greece): a generalized additive modelling approach. Mar Biol 152:1319-1331

Katsanevakis S (2009a) Estimating abundance of endangered marine benthic species using distance sampling through SCUBA diving: the Pinna nobilis (Mollusca: Bivalvia) example. In: Columbus AM, Kuznetsov L (eds) Endangered species: new research. Nova Science Publishers, New York, p 81-115

Katsanevakis S (2009b) Population dynamics of the endangered fan mussel Pinna nobilis in a marine lake: a metapopulation matrix modelling approach. Mar Biol 156:1715-1732

Katsanevakis S, Thessalou-Legaki M (2007) First record of Alicia mirabilis (Anthozoa: Actiniaria) from the Aegean Sea and density assessment with distance sampling in a site of high abundance. Mar Biol Res 3:468-472

Katsanevakis S, Lefkaditou E, Galinou-Mitsoudi S, Koutsoubas D, Zenetos A (2008) Molluscan species of minor commercial interest in Hellenic Seas: distribution, exploitation and conservation status. Medit Mar Sci 9:77-118

Kinne O (2006) Protecting nature. Endang Species Res 1:1-2 (previously 0:1-24, 2004)

Klein J, Verlaque M (2008) The Caulerpa racemosa invasion: a critical review. Mar Pollut Bull 56:205-225

> Kulbicki M, Sarramégna S (1999) Comparison of density estimates derived from strip transect and distance sampling for underwater visual censuses: a case study of Chaetodontidae and Pomacanthidae. Aquat Living Resour 12:315-325

Letourneur Y, Kulbicki M, Labrosse P (1998) Spatial structure of

Editorial responsibility: Riccardo Cattaneo-Vietti,

Genova, Italy commercial reef fish communities along a terrestrial runoff gradient in the northern lagoon of New Caldonia. Environ Biol Fishes 51:141-159

Marques FFC, Buckland ST (2004) Covariate models for the detection function. In: Buckland ST, Anderson DR, Burnham KP, Laake JL, Borchers DL, Thomas L (eds) Advanced distance sampling: estimating abundance of biological populations. Oxford University Press, New York, p 31-47

> Piazzi L, Balata D, Ceccherelli G, Cinelli F (2001) Comparative study of the growth of two co-occurring introduced green algae Caulerpa taxifolia and Caulerpa racemosa along the Tuscan coast (Italy, western Mediterranean). Cryptogam Algol 22:459-466

Pink M, Pratt TC, Fox MG (2007) Use of underwater visual distance sampling for estimating habitat-specific population density. N Am J Fish Manag 27:246-255

R Development Core Team (2006) R: a language and environment for statistical computing. R Foundation for Statistical Computing, Vienna. Available at: www.R-project.org

Rabaoui L, Tlig-Zouari S, Ben Hassine OK (2007) Distribution and habitat of the fan mussel Pinna nobilis Linnaeus, 1758 (Mollusca: Bivalvia) along the northern and eastern Tunisian coasts. Cah Biol Mar 49:67-78

> Richardson CA, Kennedy H, Duarte CM, Kennedy DP, Proud SV (1999) Age and growth of the fan mussel Pinna nobilis from south-east Spanish Mediterranean seagrass (Posidonia oceanica) meadows. Mar Biol 133:205-212

Seber GAF (1982) The estimation of animal abundance and related parameters. Macmillan, New York

Streftaris N, Zenetos A (2006) Alien marine species in the Mediterranean - the 100 'worst invasives' and their impact. Medit Mar Sci 7:87-118

Thomas L, Laake JL, Rexstad E, Strindberg S and others (2006) Distance 6.0, Release Beta 3. Research Unit for Wildlife Population Assessment, University of St. Andrews. Available at: www.ruwpa.st-and.ac.uk/distance/

Thompson WL (2004) Sampling rare or elusive species: concepts, designs, and techniques for estimating population parameters. Island Press, Washington, DC

Thompson WL, White GC, Gowan C (1998) Monitoring vertebrate populations. Academic Press, San Diego, CA

Thresher RE, Gunn JS (1986) Comparative-analysis of visual census techniques for highly mobile, reef-associated piscivores (Carangidae). Environ Biol Fishes 17:93-116

> Vázquez-Luis M, Sanchez-Jerez P, Bayle-Sempere JT (2008) Changes in amphipod (Crustacea) assemblages associated with shallow-water algal habitats invaded by Caulerpa racemosa var. cylindracea in the western Mediterranean Sea. Mar Environ Res 65:416-426

> Verlaque M, Durand C, Huisman JM, Boudouresque CF, Le Parco Y (2003) On the identity and origin of the Mediterranean invasive Caulerpa racemosa (Caulerpales, Chlorophyta). Eur J Phycol 38:325-339

Vicente N, Moreteau JC (1991) Statut de Pinna nobilis L. en Méditerranée (Mollusque Eulamellibranche). In: Boudouresque $\mathrm{CF}$, Avon $\mathrm{M}$, Gravez V (eds) Les espèces marines à protéger en Méditerranée. GIS Posidonie, Marseille, p 159-168

Williams BK, Nichols JD, Conroy MJ (2002) Analysis and management of animal populations. Academic Press, San Diego, CA

Wood SN (2000) Modelling and smoothing parameter estimation with multiple quadratic penalties. J R Stat Soc Ser B Stat Methodol 62:413-428

Wood SN (2006) Generalized additive models: an introduction with $\mathrm{R}$ (texts in statistical science). Chapman \& Hall/CRC, Boca Raton, FL

Submitted: July 31, 2009; Accepted: October 21, 2009

Proofs received from author(s): December 18, 2009 